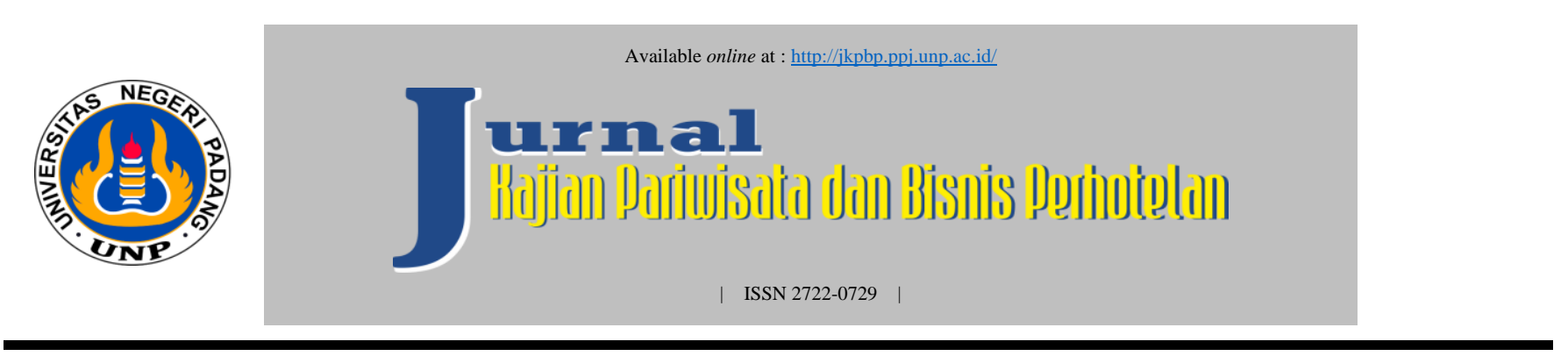

\title{
Pengaruh Service Quality Terhadap Kepuasan Tamu Menginap di UNP Hotel \& Convention
}

\author{
Eva Lusiyana ${ }^{1}$ Kasmita $^{2}$ \\ ${ }^{1}$ Univesitas Negeri Padang \\ ${ }^{2}$ Universitas Negeri Padang \\ e-mail: evalusiyana2017@gmail.com, kasmita70@fpp.unp.ac.id
}

\begin{abstract}
ABSTRAK
Penelitian ini diangkat dari pengamatan penulis mengenai service quality yang belum dijalankan dengan baik sehingga menemukan complain dari tamu. Penelitian ini memiliki tujuan mengungkapkan seberapa besar pengaruh service quality terhadap kepuasan tamu. Jenis deskriptif kuantitatif dengan hubungan kausal merupakan jenis penelitian yang digunakan pada penelitian ini. Dalam penelitian ini terdiri dari dua variabel yaitu service quality sebagai variabel bebas dan kepuasan tamu sebagai variabel terikat. Tamu yang pernah menginap di UNP Hotel \& Convention adalah populasi dalam penelitian ini dengan menggunakan teknik non probability sampling dengan jumlah sampel sebanyak 80 responden. Pengumpulan data penelitian menggunakan angket/kuisioner dengan 5 pilihan jawaban, yang telah diuji validitas dan reliabilitasnya. Pengujian hipotesis menggunakan analisis regresi linear. Hasil penelitian menunjukan bahwa service quality berpengaruh signifikan terhadap kepuasan tamu menginap di UNP Hotel \& Convention dengan besaran kontribusi pengaruh 13,2\%, dan koefisien regresi sebesar 0,426. Service quality pada katagori baik (66,25\%), didapatkan nilai F 11.861, nilai t 3.437. Dengan saran lebih memperhatikan grooming karyawan, kebersihan fasilitas dan kehandalan dalam melayani kebutuhan tamu.
\end{abstract}

Kata kunci : Service Quality, Kepuasan Tamu. 


\section{PENDAHULUAN}

Sektor ekonomi terpenting di Indonesia salah satunya adalah dunia pariwisata. Pariwisata merupakan aktivitas yang memiliki maksud untuk melangsungkan jasa pariwisata, membudidayakan daya dan objek wisata serta usaha pariwisata lain yang terkait di dalam bidang itu [1]. Salah satu provinsi di Indonesia adalah Sumatera Barat yang mempunyai kawasan pariwisata yang lumayan besar. Sumatera Barat menyimpan sejumlah destinasi wisata yang menarik, keindahan alam yang sangat bagus dan kultur yang masih melekat disetiap wilayah.

Ibu kota dari Sumatera barat yaitu Kota Padang. Akibat dari berkembangannya objek dan daya tarik yang berada di Sumatera barat, Kota padang saat ini telah memiliki berbagai insfrastruktur seperti hotel dan penginapan, sarana transportasi dan lainnya. Potensi wisata seperti wisata alam (pantai, pegunungan dan panorama alam), wisata kebudayaan (seni tradisional), wisata bahari (kunjungan pulau-pulau), wisata kuliner dan lain lain merupakan beberapa potensi yang ada di Kota Padang.

Akomodasi merupakan sebuah kebutuhan bagi para wisatawan ketika melakukan perjalanan wisata. Kualitas akomodasi meliputi aspek kenyamanan kamar, kebersihan akomodasi, keamanan, kualitas makanan, kondisi fisik dan efesiensi serta sikap karyawan.

Dunia bisnis untuk sekarang ini para investor lebih ingin untuk membangun hotel besar dikarenakan bisnis ini banyak mendatangkan keuntungan dengan begitu sektor perhotelan saat ini berkembang dengan pesat sehingga persaingan hotel-hotel saat ini bersaing dengan ketat. Oleh karena itu, hotel-hotel mulai memperbaiki manajemen dalam mengatur operasional suatu hotel serta ikut membantu dinas pariwisata agar wisata di daerah tersebut dapat berkembang dan bisa menaikan tingkat hunian kamar di daerah tersebut.

Kepuasan konsumen yaitu sebuah kedudukan dalam memenuhi kebutuhan, keinginan, dan asa dari konsumen yang dapat terpenuhi agar konsumen dapat melakukan pembelian ulang atau kesetiaan yang berlanjut. Service Quality yang diberikan karyawan merupakan salah satu komponen terpenting dalam membentuk kepuasaan pelanggan. Jasa pelayanan adalah sekumpulan nilai yang berkemampuan guna baik secara spesifik maupun inplisit atas kemudahan menjelang memperoleh muatan maupun kebijakan pelayanan [2] .

Kepuasan adalah tanggapan seseorang suka atau tidak suka yang dihasilkan berasal memadankan kapabilitas produk yang dirasakan dengan kepercayaan jika kapabilitas jauh dari kepercayaan, maka konsumen tidak puas[3]. Pelanggan akan puas jika harapan sesuai dengan yang diharapakan..Hasil pra penelitian penulis menemukan Adanya tamu complaint terhadap Service Quality karyawan di UNP Hotel \& Convention. Selanjutnya respon karyawan hotel sangat lambat dalam merespon tamu di UNP Hotel \& Convention. Kemudian tidak terpenuhi harapan tamu di UNP Hotel \& Convention. Selanjutnya tidak diulangnya pesanan tamu di UNP Hotel \& Convention. Dan yang terakhir pramusaji kurang pemahaman pada Menu yang ada di UNP Hotel \& Convention.

\section{METODOLOGI PENELITIAN}

Jenis penelitian ini deskriptif kuantitatif bentuk asosiatif kausal. asosiatif kausal merupakan sebab akibat yang memiliki hubungan dalam penelitian, jadi terdapat variabel independent, (variabel yang mempengaruhi) dan dependen (dipengaruhi) [4]. Variabel bebas dan variabel terikat merupakan variabel yang terdapat dalam penelitian ini. Tamu yang pernah menginap di UNP Hotel \& Convention merupakan populasi dalam penelitian ini dengan menggunakan jenis non probability sampling. Data primer dan data sekunder adalah jenis data yang digunakan yang digunakan dalam penelitian ini. Teknik pengumpulan data dilakukan dengan cara menyebar kuesioner yang terstruktur. Sampel penelitian ini mengunakan untuk diuji coba sebanyak 80 responden. Uji persyaratan analisis dilakukan dengan uji normalitas, uji homogenitas dan uji linearitas. Pengujian hipotetis penelitian menggunakan analisis regresi linear sederhana. 


\section{HASIL PENELITIAN DAN PEMBAHASAN}

Perolehan data dala penelitian meliputi distribusi frekuensi tentang service quality serta distribusi frekuensi tentang kepuasan

Tabel 1. Distribusi Frekuensi Variabel Service Quality

\begin{tabular}{|c|c|c|c|}
\hline Kategori & Rentang Skor & F & \% \\
\hline Sangat baik & $\geq 84$ & 3 & 3,75 \\
\hline Baik & $\mathbf{7 0}-<\mathbf{8 4}$ & $\mathbf{6 0}$ & $\mathbf{7 5}$ \\
\hline Cukup & $93,3<116,6$ & 17 & 21,25 \\
\hline Buruk & $70,5-<93,3$ & 0 & 0 \\
\hline Sangat buruk & $<70,5$ & 0 & 0 \\
\hline \multicolumn{2}{|c|}{ Jumlah } & 80 & 100 \\
\hline
\end{tabular}

Sumber : Data Primer 2021 (Telah diolah)

Berdasarkan tabel 1 dapat dijelaskan responden mengemukakan bahwa service qualiy di UNP Hotel \& Convention sangat baik 3,75 \%, responden mengemukakan baik $75 \%$, namun 21,25\% responden mengemukakan cukup, dan tidak ada responden yang mengemukakan service quality di UNP Hotel \& Convention buruk dan sangat buruk. Berdasarkan perhitungan statistic variabel Service Qualiy berada pada Klasifikasi skor $70-<84$ menunjukan katagori baik dengan presentase $75 \%$.

Tabel 2. Distribusi Frekuensi Variabel Kepuasan Tamu

\begin{tabular}{|c|c|c|c|}
\hline Kategori & Rentang Skor & F & \% \\
\hline Sangat baik & $\geq 75,99$ & 4 & 5 \\
\hline Baik & $\mathbf{6 3 , 3 3 - < 7 5 , 9 9}$ & $\mathbf{5 3}$ & $\mathbf{6 6 , 2 5}$ \\
\hline Cukup & $50,67-<63,33$ & 23 & 28,75 \\
\hline Buruk & $38,01-<50,67$ & 0 & 0 \\
\hline Sangat buruk & $<38,01$ & 0 & 0 \\
\hline \multicolumn{2}{|c|}{ Jumlah } & 80 & 100 \\
\hline
\end{tabular}

Sumber : Data Primer 2021 (Telah diolah)

Berdasarkan tabel 2 dapat dijelaskan responden mengemukakan bahwa kepuasan tamu di UNP Hotel \& Convention sangat baik $5 \%$, responden mengemukakan baik 66,25 \%,namun 28,75\% responden mengemukakan cukup, dan tidak ada responden yang mengemukakan kepuasan tamu di UNP Hotel \& Convention buruk dan sangat buruk. Berdasarkan perhitungan statistik variabel kepuasan tamu berada pada klasifikasi skor 63,33 $-<75,99$ menujukkan kategori baik dengan persentase $\mathbf{6 6 , 2 5} \%$.

\section{Uji Persyaratan Analisis}

\section{Uji Normalitas.}

Data yang diterima mengemukakan bahwa nilai Signifikan untuk Service Quality adalah 0,206 dan untuk variabel kepuasan tamu adalah 0.301. Dengan nilai signifikan besar daripada 0,05, hal ini dapat disimpulkan bahwa kedua variabel berdistribusi normal. 


\section{Uji Homogenitas}

Bersumber dari Hasil yang diterima mengemukakan bahwa homogenity test diperoleh, nilai Sig adalah 0,115 dengan batas sigg besar dari 0,05. Hal ini dapat ditarik kesimpulan bahwa data bersifat homogeny karena data berasal dari populasi yang berjenis sama.

\section{Uji Linearitas}

Bersumber dari test linearity yang telah dilakukan diterima nilai sign. 0,841 dengan batas signifikansi > 0,05. Hal ini dapat disimpulkan bahwa kedua variabel memiliki hubungan linear dan signifikan.

\section{Pengujian Hipotesis}

\section{Analisis Regresi Linear Berganda}

\section{a. Uji F}

Uji $\mathrm{F}$ digunakan untuk melihat berarti atau tidaknya pengaruh variabel terikat secara serentak. Hasil uji F dapat dilihat pada tabel tabel berikut :

Tabel 3. Hasil Signifikasi Uji F

ANOVA ${ }^{b}$

\begin{tabular}{|ll|r|r|r|c|c|}
\hline \multicolumn{2}{|l|}{ Model } & $\begin{array}{r}\text { Sum of } \\
\text { Squares }\end{array}$ & df & $\begin{array}{c}\text { Mean } \\
\text { Square }\end{array}$ & F & Sig. \\
\hline 1 & Regression & 436.762 & 1 & 436.762 & 11.816 & .001 \\
& Residual & 2883.238 & 78 & 36.965 & & \\
& Total & 3320.000 & 79 & & & \\
\hline
\end{tabular}

Berdasarkan pada hasil diatas, didapat nilai $\mathrm{F} 11.816$ dengan sign 0,001 $<0,05$ sehingga, bisa disimpulkan bahwa hipotesis yang diterima adalah Ha dan Hoditolak dan adanya pengaruh yang jelas dan relevan antara Service Quality dengan, Kepuasan Tamu di UNP Hotel \& Convention.

\section{b. Persamaan Regresi}

Diperoleh persamaan regresi produktivitas kerja berdasarkan tabel berikut :

Tabel 4. Hasil Uji Koefisien Regresi Sederhana

\begin{tabular}{|c|c|c|c|c|c|c|}
\hline \multirow{2}{*}{\multicolumn{2}{|c|}{ Model }} & \multicolumn{2}{|c|}{$\begin{array}{c}\text { Unstandardized } \\
\text { Coefficients } \\
\end{array}$} & \multirow{2}{*}{\begin{tabular}{|c}
$\begin{array}{c}\text { Standardize } \\
\mathrm{d} \\
\text { Coefficients }\end{array}$ \\
Beta
\end{tabular}} & \multirow[b]{2}{*}{$\mathrm{T}$} & \multirow[b]{2}{*}{ Sig. } \\
\hline & & B & $\begin{array}{l}\text { Std. } \\
\text { Error }\end{array}$ & & & \\
\hline \multirow[t]{2}{*}{1} & (Constant & 34.409 & 9.215 & & 3.734 & .000 \\
\hline & $\mathrm{TX}$ & .426 & .124 & .363 & 3.437 & .001 \\
\hline
\end{tabular}

a. Dependent Variable:

TY

Untuk memahami berapa koefisien regresi antara variable Service Quality (X) terhadap Kepuasan Tamu (Y). sehingga, dapat diamati pada persamaan dibawah ini: 
$\mathrm{Y}=\mathrm{a}+\mathrm{bx}$

$\mathrm{Y}=34.409+.426$

Bersumber dari data diatas, terdapat koefisien regresii sebesar .426 dengan nillai sig. $0,001<0,05$. Yang berarti 0,426 satuan kepuasan tamu akan ditingkatkan dari 1 satuan service quality.

\section{c. Koefisien Determinasi}

Dalam mengetahui seberapa besar pengaruh anatar variabel dalam penelitian ini menggunakan koefisien determinasi. Hasill pengujian determinasi bisa diamati dari hasil R square pada analisis linear sederhana pada table berikut :

Tabel 5. Hasil Koefisien Determinasi (R Square)

\begin{tabular}{|l|r|r|r|r|}
\hline Model & R & R Square & $\begin{array}{c}\text { Adjusted R } \\
\text { Square }\end{array}$ & $\begin{array}{c}\text { Std. Error of } \\
\text { the Estimate }\end{array}$ \\
\hline 1 & $.363^{\mathrm{a}}$ & .132 & .120 & 6.07985 \\
\hline
\end{tabular}

Berdasakan tabel di atas, koefisien determinasi yang diterima sebesar 0,132 hal ini berarti variabel Service quality berpengarh sebanyak 13,2\% terhadap Kepuasan tamu di UNP Hotel \& Covention dan 86,8\% dipengaruhi oleh variabel lainnya.

\section{Pembahasan}

\section{A. Pembahasan}

Berdasarkan hasil penelitian yang dilakukan, maka bisa dijelaskan tentang Service Quality dan kepuasan tamu di UNP Hotel \& Convention dan pengaruh diantara satu variabel yang mempengaruhi dengan variabel yang dipengaruhi. Dari anallisa dapat dilihat bahwa variabel independen (Service Quality) sgnifikan terhadap variabel dependen (Kepuasan Tamu), Penjelasannya sebagai berikut:

\section{Service Quality}

Berdasarkan hasil penelitian, menunjukan bahwa Service quality di UNP Hotel \& Convention jika di tinjau dari aspek Tangible termasuk katagori baik. Kebersihan peralatan kerja yang digunakan karyawan dan tamu dalam kondisi baik, tamu dengan mudah mendapatkan pelayanan yang di inginkan namun masih terdapat ketidakpuasan pelangan dari segi kerapian seragam karyawan dan kebersihan fasilitas restoran dan toilet. Ditinjau dari aspek Emphaty termasuk katagori cukup. Karyawan rama tamah pada tamu, namun masih terdapat ketidakpuasan pelangan dari segi karyawan belum mengutamakan kepentingan pelangan,karyawan melayani pelangan masih ada yang belum sopan santun, karyawan belum seluruhnya memahami cara berkomunikasi dengan tamu dan tidak membeda-bedakan tamu VIP.

Aspek Reability termasuk katagori baik. Karyawan memberikan pelayanan sesuai dengan keinginan tamu, menyampaikan informasi dengan benar, memberikan pelayanan yang cepat, tepat dengan waktu yang tepat dan menggunakan alat bantu saat menghandel breakfast. Namun masih terdapat ketidak puasan pelangan dari segi prosedur pengurusan reservasi kamar, event dan transaksi belum di lakukan cepat dan akurat.

Aspek Responsiveness termasuk katagori baik. Karyawan selalu memberikan pelayanan dengan cermat dan cepat. Namun masih terdapat ketidakpuasan pelangan dari segi karyawan belum memberikan pelayanan dengan waktu yang tepat, cepat dalam merespon keluhan pelangan. 
Aspek Assurance termasuk katagori cukup. Karyawan memberikan kepastian biaya dengan pelayanan yang baik namun masih terdapat ketidak puasan pelangan dari segi pengetahuan karyaan dalam melayani tamu pada saat breakfast dengan waktu yang tepat.

Berdasarkan penjelasan di atas menunjukkan bahwa Service quality sangat penting di terapkan bagi karyawan untuk memenuhi kepuasan tamu. Halini sejalan dengan pendapat[5] bahwa "Kualitas pelayanan adalah kecocokan untuk pemakaian dan sesuai dengan permintaan (finess for use and conformanceto requirement)". Defenisi tersebut menerangkan harapan dari pelanggan karena kualitas layanan menggambarkan sebuah layanan penawaran produk dan jasa layanan yang dapat menghasilkan faedah bagi konsumen.

\section{Kepuasan Tamu}

Berdasarkan hasil penelitian, menunjukan bahwa kepuasan tamu di UNP Hotel \& Convention jika di tinjau dari aspek tercapainya harapan tamu termasuk katagori cukup. Pelayanan yang diberikan sesuai dengan harapan pelangan dan pelayanan yang diterima tamu sesuai dengan yang di janjikan, dari aspek terpenuhinya harapan tamu termasuk katagori baik, fasilitas dapat memenuhi segala kebutuhan tamu selama menginap dan disambut baik oleh karyawan hotel, namun masih terdapat ketidakpuasan pelangan dari segi pelayanan yang belum tepat waktu dan tamu belum merasa di pentingkan saat menginap.

Aspek tercapainya keinginan pengunjung termasuk katagori cukup. Keinginan tamu terpenuhi dengan pelayanan yang diberikan dan merasa nyaman saat menginap. Namun masih terdapat ketidakpuasan dari segi kualitas pelayanan yang diberikan belum sesuai dengan yang di janjikan, belum cepat dan tepat dalam memenuhi harapan tamu dan tamu belum di sambut dengan baik oleh karyawan.

Aspek adanya keinginan untuk memakai produk dan jasa itu kembali termasuk katagori cukup. Tamu akan menginap kembali jika berkunjung dan merekomendasikan kepada orang lain dengan pelayanan yang cepat dan tepat. Namun masih terdapat ketidakpuasan pelangan yang disebabkan oleh fasilitas dan pelayanan yang belum baik.

Aspek adanya keinginan untuk merekomendasikan termasuk katagori baik. Tamu bekeinginan merekomendasikan kepada orang lain, karena sebagian besar tamu UNP Hotel \& Convention menyenangkan dan tepat untuk mengajak orang lain menginap di UNP Hotel \& Convention. Namun masih terdapat ketidakpuasan pelanggan dari segi pengalaman yang kurang menyenangkan saat menginap dan berkeinginan untuk merekomendasikan kualitas pelayanan yang baik dan cepat kepada orang lain.

Berdasarkan penjelasan di atas menunjukkan bahwa Service quality sangat penting di terapkan bagi karyawan untuk memenuhi kepuasan tamu, [6] mendefinisikan kepuasan konsumen seumpama penaksiran secara sadar atau penilaian kognitif menyangkut apakah kinerja produk relative elok atau buruk atau apakah produk bersangkutan cocok atau tidaknya dengan sasaran atau pemakainya.

\section{Pengaruh Service Quality terhadap Kepuasan Tamu Karyawan di UNP Hotel \& Convention}

Bersumber dari pengujian yang dilakukan dalam mengetahui seberapa besarnya pengaruh service quaity terhadap kepuasan tamu di UNP Hotel \& Convention yang dilakukan dengan bantuan aplikasi diperoleh nilai koefisien determinasi R Square 0,132 artinya pengaruh variabel $\mathrm{X}$ terhadap variabel $\mathrm{Y}$ adalah sebesar $0,132(13,2 \%)$. Sedangkan 86,8\% dipengaruhi oleh faktor lain. Maka Ha yang diterima yang dijadikan hipotesis dalam penelitian sedangkan Ho ditolak. 
Service quality berpengaruh atas Kepuasan tamu di UNP Hotel \& Convention karena service quality merupakan salah satu factor, yang bisa mempengaruhii kepuasan tamu. sejalan dengan pendapat [7] "kualitas pelayanan dapat di definisikan sebagai tahap control yang diharapkan dan pengendalian atas tahap control tersebut untuk memenuhi kemauan pelanggan..

Hasil ini seiring dengan hasil riser yang dilakukan [8] menunjukkan bahwa kepuasan dipengaruhi oleh service quality secara simultan. Penelitian lain yang dilakukan oleh Nugroho, adapun [9] hasil penelitian menunujukkan bahwa kepuasan konsumen baik secara parsial dan simultan dipengaruhi oleh service quality

Bersumber dari hasil riset tersebut dapat ditarik kesimpulan disimpulkan bahwa service quality berpengaruh secara signifikan. Service quality berpengaruh terhadap kepuasan tamu di UNP Hotel \& Convention sebesar $(0,132) 13,2 \%$ namun terdapat faktor lain juga mempengaruhi kepuasan tamu. Hasil penelitian menunjukan bahwa setiap 0,132 satuan peningkatan service quality maka akan meningkatkan 0,132 satuan kepuasan tamu di UNP Hotel \& Convention.

\section{KESIMPULAN}

Bersumber dari hasil riset yang telah dilakukan di UNP Hotel \& Convention dapat ditarik kesimpulan sebagai berikut:

1. Service Quality di UNP Hotel \& Convention menunjukan kategori baik dengan persentase $75 \%$

2. Kepuasan Tamu di UNP Hotel \& Convention menunjukan secara keseluruhan dengan kategori baik dengan persentase $66,25 \%$

3. Service quality berpengaruh signifikan terhadap kepuasan tamu di UNP Hotel \& Convention dengan koefisien regresi sebesar 0.,426 dengan nilai sig $0 ., 001<0,05$, artinya setiap peningkatan 1 satuan motivasi akan menaikkan 0,426 produktivitas kerja. Dan diperoleh koefisien determinasi sebesar $(0,132)$ 13,2\% dan 86,8\% dipengaruhi oleh faktor lain dengan nilai R Square sebesar 0,132. 


\section{DAFTAR PUSTAKA}

[1] I. G. B. R. Utama, Pemasaran Pariwisata. Yogyakarta: Penerbit Andi, 2017.

[2] Z. Yamit, Manajemen Kualitas Produk dan Jasa. Yogyakarta: Ekonisia, 2010.

[3] U. Fariza, N. Rachma, and M. Hufron, "Pengaruh Service Quality terhadap Customer Loyalty Dimediasi Customer Satisfaction dan Switching Cost Sebagai Variabel Moderating.," J. Ris. Manaj., vol. 8 No.15, pp. 100-114, 2019.

[4] Sugiyono, Metode Penelitian Kuantitaif. Bandung: Alfabeta, 2018.

[5] F. Tjiptono, Service Manajemen: Mewujudkan layanan Prima. Yogyakarta: Andi, 2012.

[6] F. Tjiptono, Pemasaran Jasa. Yogyakarta: Andi, 2014.

[7] B. Simamora, Membongkar Kotak Hitam Konsumen. Jakarta: Gramedia Pustaka Utama, 2003.

[8] D. Baetie, "Pengaruh Kualitas Pelayanan Terhadap Kepuasan Tamu di Hotel Niagara Prapat Provinsi Sumatera Utara," JOM FISIP, vol. 5 No. 1, pp. 1-13, 2018.

[9] M. F. Nugroho, "Pengaruh Service Quality Terhadap Kepuasan Konsumen Honda Utama Motor Yogyakarta," Univeristas Negeri Yogyakarta, 2016. 